\title{
The missing link: toward an assessment of innovation capacity in health care organizations
}

\author{
Pieter J. Kievit ${ }^{1 *}$, Jeanette Oomes ${ }^{2}$, Marianne Schoorl ${ }^{2}$ and Piet Bartels ${ }^{2}$
}

\author{
* Correspondence: p.j.kievit@ \\ westfriesgasthuis.nl \\ ${ }^{1}$ West Frisian Academy, Westfries \\ Medical Centre, Maelsonstraat 3, \\ 1624 NP Hoorn, the Netherlands \\ Full list of author information is \\ available at the end of the article
}

\begin{abstract}
The health care sector shows a disjunction between the well-understood necessity for change and the capacity to realize it. Conventional management strategies and traditional means of influencing professionals often fail to deliver projected outcomes. We address this issue from a different angle. An organization's capacity for change is determined by the combination of power distribution, value system and change readiness, which should be analyzed not as formal qualities but as aspects of the organization as a social system, disclosing a reality beneath the surface of mission statements, quality policy and management models. We describe a method to analyse the identity of an organization as a social system with respect to its innovation potential. This identity shows in the rules of discourse determining what is valid communication and which are the sources of impact of arguments in a communicative interaction leading to decisions. We present two case studies in which groups of physicians argue in favor of respectively against the availability of physician-assisted death (PAD) for terminal patients.
\end{abstract}

Keywords: Health care innovation, Innovation profile, Quality management, Systems theory, Patient participation, Shared decision making, Discourse analysis

Compared to other aspects of diffusion research there have been relatively few studies of how the social or communication structure affects the diffusion and adoption of innovations in a system. [1].

\section{Background}

In health care organizations, structure and process innovation are considered to be key drivers for the improvement of both efficiency and experienced quality of care [2, 3]. In everyday practice, however, innovation projects frequently fail to meet their targets and to deliver sustainable outcomes [4].

This failure points to misunderstandings about the conditions for innovation and sustained quality improvement in health care organizations.

According to Scott [5], organizations can be seen as either rational, productive systems aiming at optimizing input-output ratios or as natural, adaptive social systems that evolve via spontaneous, indeterminate processes, "trying to survive in their environment". This

(c) The Author(s). 2018 Open Access This article is distributed under the terms of the Creative Commons Attribution 4.0 International License (http://creativecommons.org/licenses/by/4.0/), which permits unrestricted use, distribution, and reproduction in any medium, provided you give appropriate credit to the original author(s) and the source, provide a link to the Creative Commons license, and indicate if changes were made. 
dual nature of organizations as instruments to reach a specific goal and as living environments for social interaction has deep roots in the literature on organization studies as shown by Lincoln and Kalleberg [6], Orru et al. [7], Scott et al. [8], Hogg and Terry [9], Scott and Davis [10] and Capra and Luisi [11].

Innovation theory has tried to reconcile these two concepts of the organization and to merge them into mixed models in which proven best practices are implemented by means of social engineering aimed at individual attitude-illustrated by "Maier's law" E $=\mathrm{Q} \times \mathrm{A}$ (the effectiveness $(\mathrm{E})$ of an intervention is equal to the quality $(\mathrm{Q})$ of the solution multiplied by the acceptance (A) of the idea) [12]. This approach, combining the formal and informal structure of organizations [13], has found its way into most paradigms for quality improvement in health organizations such as the EFQM, Continuous Quality Improvement, Total Quality Management, Six Sigma, LEAN, FADE and PDCA [14]. But even an open and all-encompassing innovation paradigm like the Malcolm Baldrige Health Care Criteria for Performance Excellence (HCPE) which combines interventions in organization design, strategy, systems and human capital to create long-term effectiveness (in terms of process design combined with clinical outcome) does not outperform non-HCPE hospitals on this parameter [15]. HCPE hospitals however do score substantially better on experienced quality of care. Obviously, "emphasizing a broadly communicated mission, a supportive learning culture, universal measurement and benchmarking and systematic process improvement" [16] result in greater awareness of patient's needs and interests, but the causality behind this correlation remains unclear.

In addition to these generalized approaches, Lee [17] and Lee and Kim [18], for instance, refer to the multifactorial nature of quality in health service, depending on the perspective of the parties involved. They present a survey of models in which "the perceptions of a variety of stakeholders including patients, physicians, nurses and others to create a more comprehensive view of health service quality" are leading.

But despite all efforts to implement standardized models for quality improvement, the health care sector suffers from a persistent immunity to change as pointed out by Berwick [19] and confirmed in subsequent studies by, for instance, Greenhalgh et al. [20] and Grol and Wensing [21]. There appears to be a disjunction between the generally well-understood necessity for change and the intrinsic capacity to realize it. This so-called quality chasm was defined by the Institute of Medicine as a "disability of health care delivery systems to translate knowledge into practice" [22]. Underlying all concepts of model-management and stage-gate innovation, there seems to be a hidden dynamics in health care organizations, either stimulating or obstructing the effects of interventions aimed at quality improvement.

The purpose of this paper is to analyse this hidden dynamics and to develop an approach to assess the capacity for innovation and sustainable change in healthcare organizations. We look at them through the analytic lens of the theory of social systems and take their compound nature into account. In this way, we aim to construct "the missing link between innovation process design and innovation potential at the organization level" [23] in order to enhance the success rate of innovation projects aimed at quality improvement. These are the "conditions and factors facilitating and inhibiting innovations in healthcare" as outlined by Länsisalmi et al. [24], knowledge of which is essential if innovation is to be successfully implemented, adopted and assimilated. Our 
research question is how can the potential for change of a healthcare organization be assessed in order to select an appropriate innovation and the best means to ensure implementation? This question addresses the preconditions for sustainable quality improvement. Clarifying it is vital to decide which innovation is appropriate and feasible in a particular situation and which is the best way to implement and adopt it.

\section{Review of literature}

When Atul Gawande published his proposals for quality control, cost control and innovation in healthcare, setting the Cheese Cake Factory as an example for customer satisfaction through process management and people control, he sparked a discussion, not only on the best way to improve patient care but also on the very nature of health care delivery and professional attitude $[25,26]$.

\section{Innovation potential}

The discussion underlying this exchange about a restaurant chain as model for optimizing hospital service revolves around the question of quality assurance in healthcare and how to improve it. Berwick [27] summarizes the two traditional approaches as "the era of professional dominance", where the individual professional is responsible for the quality of his/her own performance, based on respect for his/her unique expertise, and "the era of accountability", where quality control is guaranteed by formalization: process design, measurement and material incentives. However, as research has shown, neither the formal properties of an organization nor the characteristics of individual professionals suffice as predictor for the lasting impact of quality improvement initiatives [20].

Rogers, in the most influential theory of innovation in the public sector [28], even draws the conclusion that "formalization (defined as the degree to which an organization emphasizes following rules and procedures in the role performance of its members) was found to be related negatively to organizational innovativeness" [29]. As to the influence of characteristics of individual professionals on the innovation potential of an organization, there is a wide variety of research denying any significant connection between a person's age, education, experience or gender and the ability to adopt change. For more on this topic, see for instance Cummings and Worley [30] and Bakken et al. [31] who explore questions like "Why is change so difficult even when everyone and everything is aligned around the goal" and "Why is the gap so great between our intentions, even our decisions - and what we are actually able to bring about" [32].

One of the conclusions of the systematic review by Greenhalgh et al. [20] into the conditions for diffusion of innovation in health organizations is that the ability of an organization to realize change and its capacity for innovation cannot be derived from its formal properties (as "rational productive systems") nor be reduced to the characteristics of individuals being part of that organization (as "adaptive social system"). Key factor in determining an organization's potential for change according to Greenhalgh et al. is the set of values which constitute the corporate culture [20]. It is this aspect of culture as a set of values where Berwick [27] sees the domain of a third era of quality assurance and improvement in healthcare. He calls it the "moral era" where the community of (medical) professionals adheres to a set of values which convene on aspects of professional decency and shared responsibility. 


\section{Compound character of health delivery organizations}

Rogers' standard handbook does not address the problem of the compound nature of organizations in the health care sector as an impeding factor in the adoption of innovation aimed at quality improvement. A number of studies have pointed to the challenges posed by institutional complexity where multiple institutional logics and competing interests interact and collide.

Reay and Hinings [33] describe the tension between "the logics of medical professionalism and business-like health care" each with "their own organizing principles and different set of behaviors". Provan and Kenis [34] refer to the "struggle for legitimacy among participants in different internal networks" leading to tensions and instability in the organization. Kirkpatrick et al. [35] argue that calling medical professionals to management roles and thereby "turning poachers into gamekeepers" have had a positive effect on "quality improvement and innovation design with positive consequences for patient safety and satisfaction". Degeling et al. [36] plead for a strengthening of clinical governance by combining the interests of "both clinical practice and organizational structure", thereby "integrating financial control, service performance and clinical quality". Greenwood et al. [37] explore "the repertoire of strategies and structures that organizations deploy to cope with multiple, competing demands" from "plural institutional logics", and Glouberman and Mintzberg [38] as early as 2001 posed the question why "overall social control of the systems of healthcare is so enormously different to effect"-describing the sector as being "differentiated into four different worlds - four sets of activities, four ways of organizing, four unreconciled mindsets - care, cure, control, community". The way in which competing systems of situational logic hampered the implementation of an evidence-based technological improvement in patient care is studied in detail by Greenhalgh et al. who conclude that "the GPs or administrators refused fully to comply (with the implementation of the new technology) because they believed that the innovation threatened to subvert a dimension of valued professional commitments" [39]. Lee [17] and Lee and Kim [18] point to the "variety of stakeholders including patients, physicians, nurses and others" who are needed to "create a more comprehensive view of health service quality". Kabat [40] in Getting risk right sums up "different groups - scientists, regulators, health officials, lay advocates, journalists, business men, lawyers - are shaped by different backgrounds and motivated by different beliefs and agendas. Depending on the issue at hand, the interests of these parties may conflict or may align and reinforce one another".

\section{The organization as a social system}

In his theory of innovation in the public sector, Rogers [29] lists four aspects relevant to the implementation and adoption of innovation: the character of the innovation, dynamics of the communication channels, the time dimension and the nature of the social system involved. Key element is the organization as a social system which Rogers describes as "a set of interrelated units that are engaged in joint problem solving to accomplish a common goal" [29]. For its continuity, the system depends on structure: "We define structure as the patterned arrangements of the units in a system" [29]. In addition to the formal structure, Rogers defines informal structures as the "interpersonal networks linking a system's members, tracing who interacts with whom and under what circumstances" [29]. These 
networks form "patterns of communication" which "predict, in part, the behavior of individual members of the social system, including when they adopt an innovation" [29]. In that way, the formal and informal structure of a social system "can facilitate or impede the diffusion of innovations" [29]. However, in describing a social system as a set of relationships, Rogers' model does not account for the phenomenon of the development of an organization in reaction to a changing environment or to internal dynamics.

In order to include the aspect of organizational evolution, we refer to the theory of Luhmann. In applying Luhmann's concepts, we follow the lead of Wolf and Meissner [41] and Meissner and Sprenger [23] who have demonstrated the added value of systems theory as a paradigm to address and explain the central issue of corporate culture as key factor in creating and sustaining innovation.

A social system as conceived by Luhmann is more than the formal definition of $\Sigma=(M, \mathfrak{R})$, in which $M$ is a finite number of elements and $\mathfrak{R}$ is a number of relations $\mathrm{R} 1, \mathrm{R} 2, \mathrm{R} 3, \ldots, \mathrm{R} n$ in $M$. To this static definition, Luhmann adds the dynamics of "autopoiesis"-the development of identity in self-awareness expressed internally-defining the system's elements and their possible relationships-and externally in temporal en spatial relationships: to the system's remembered past and expected future and to the environment it perceives as the other. In this experience of the temporal and spatial other as alter, a system experiences itself simultaneously in its identity as auto.

According to Luhmann [42], the means by which a system develops and maintains its identity over time is communication. Communication is the organon of autopoiesis. Communication, be it verbal or non-verbal, direct or transmitted, factional or fictional, is more than just transferring information from an addresser to an addressee. It is the form of social interaction through which "...cultures are transmitted, relationships are sustained, identities are affirmed and social structures of all sorts are reproduced" [43, 44].

Within this context, Luhmann [42] identifies the organization as a specific kind of autopoietic social system which reproduces itself by means of a specific kind of communication: through decisions, "...implying the awareness and communication of alternatives and continuous reference to previous decisions" [45-47]. So, whereas a generic social system (or a function system like the judicial system or the science system) is defined by the phenomenon of communication in action addressing and transmitting values such as right/wrong or true/false, the organization as a system is characterized by its teleology which is expressed in a particular type of communication, the decision, with success and failure as (surrogate) end point values.

The organization as a decision-making system operates within an environment characterized by complexity, which presents itself as a potentially unlimited variety of states of affairs as context for possible decisions and ensuing actions. A system's operations however can only absorb a limited amount of complexity before being stalled in perpetual potentiality or stasis. The process of decision-making depends on an organization's capacity for complexity reduction, dealing with the tension between the secure and the insecure and the remembered and the expected. Control as condition for continuity can only be accomplished on the basis of operational simplification of the perceived reality in its complexity. According to Luhmann [42], organizations even "...arise primarily as a means to deal with complexity", thereby acting upon "...a tangled world that entails complexity" in order "to get things done" [45]. So communication in organizations is based on complexity reduction in order to be able to reach decisions. 
But communication is never a-topic, developing in a social void, but is always situational-happening in time and place-and as such context dependent. Communication as a model shows the process of interaction whereby an addresser transmits signs as bits of information referring to a state of affairs to an addressee through a medium, periodically checking the status of the transfer [48]. The actual realization of the elements in the model is the outcome of choices, limited by the context in which communication happens.

In communication-in-action, the context determines just who can act as addresser (sender) and addressee (receiver) and whereas the communication model states that communication is about a subject (referent), the context determines which subjects (or states of affairs) are permissible topics in any actual conversation and what might be the value of arguments concerning that topic. The question to be answered here is what determines the value of an argument in a discussion leading to a valid decision? Here, we ask about the sources of impact of an argument as they appear in the rules of discourse (defining a group as a particular social system): what makes one argument more effective than another in reaching a shared decision and what does that tell about the organization where the discussion takes place?

\section{Methods}

What determines an organization's capacity for change? How does it decide which innovation is a valid answer to a perceived challenge? How does it choose the implementation strategy leading to the best possible outcome?

\section{Innovation potential}

In our combined experience of many years in quality improvement and innovation management in the health care sector, there are three interacting aspects of an organization relevant to its innovation potential.

\section{Legitimacy}

Legitimacy in a social system is derived from three sources. The first is the way in which status is assigned and confirmed. Social systems attribute roles to its members and status to the roles. The status refers to power distribution in the form of formal and informal leadership or "...the control over discourse itself: who is speaking in what context" [49]. This power distribution-determining the impact of an argument-does not necessarily coincide with the hierarchy in the formal organization which is connected with titles, job description and authorization.

The second element of legitimacy is related to the inclusiveness of a system, its accessibility and its capacity for absorbing alternative views [50]. Who is allowed to participate in communication and what weight is attached to his or her arguments depend on the degree to which the system values inclusiveness, pluriformity and equality and how access and participation are granted.

The third element of legitimacy is the way in which decisions are formalized-by a word of will from an authority or by formalized procedure, restricting arbitrary power. What is addressed here is the governance structure of a system or the "processes and interactions that constitute patterns of rule" [51]. Legitimacy is determined by power 
distribution as a general character of a system as it appears in leadership, inclusiveness and governance.

\section{Values}

In adopting change, an organization will invest energy and resources, expecting a return on the investment. This investment and the expected return are expressed in a currency which relates to the values held by the organization. In health care, these currencies will generally correspond to quality of care, clinical outcomes, professional ethics, patient, satisfaction and/or economic sustainability, depending on the parties involved.

But it is not just the currency in which a value is expressed that is addressed here, but of equal importance is the quantification. Just how much of an economic or societal value is at stake in the exchange of arguments leading to a decision?

In the third place, the impact of an argument depends on the way it refers to the origin of the values it relates to. Is the value based on self-motivation, an expression of the very identity of the social system-or does it derive from an external impulse, e.g. the need to provide customer value or to comply with a government regulation or payer demand? What is addressed here is what a system holds to be important as the outcome of its activities and as rationale for its existence.

\section{Change readiness}

Is the organization ready to adopt innovation and can it accept change without risking or losing its identity? Arguments (either pro or con!) in the process of decision making can be supported by recourse to traditions, representing a superior standard and authority, or by evoking the challenges of the future, requiring a breach with time honored-but obsolete-practices.

In arguments for or against change, a shared view on evolution comes to expression: evolution as a predictable sequence of cause and effect, dominated by serial bi-conditional equivalence and based on applying "...golden rules associated with linearity: reductionism, predictability and determinism" [52] or evolution as a series of contingencies in the form of single implications asking for permanent improvisation in reaction to random occurrences.

In the third place, the change readiness of an organization as a social system depends on its self-assessment as a change agent or champion of continuity. What is addressed here is the organization's valuation of and relation to tradition. In this way, change readiness is linked to the degree of uncertainty which the organization is able to sustain as a social system.

An innovation will be successful to the degree in which its aims are compatible with the values of the organization as a system, the implementation process will be compatible with the legitimacy structure and the overall project fits in with the change readiness of the system.

Put in a matrix, the elements of an organization's innovation profile look like this:

At this point, it is crucial to remember two things. In the first place, the innovation potential of an organization is not depending on its formal qualities or the characteristics of its employees but on its dynamics as a social system expressed in discursive strategies. Second, healthcare organizations as compound organizations are the arena in which different social systems as representatives of wider societal systems such as medical 
professionals, patients and management compete for power, resources and dominance. One of the main impediments to accomplice change and innovation in compound organizations is exactly this complex interaction which needs to be analysed in order to assess which innovation is feasible under what conditions and how to implement and assimilate it.

\section{Communication and discourse}

The innovation capacity of an organization as a social system is difficult to analyse as it lacks ontological status-it is so-called construct, "a theoretical creation that is based on observations but that cannot be observed directly or indirectly" [53]. What is there to observe? Social systems are accessible for analysis because they consist of the "totality of all communication" [54] taking place and communication is a phenomenon which can be observed.

However, observing and describing singular instances of communication-in-action is not sufficient to draw conclusions about the character-and innovation capacity-of a social system. Communication is a surface phenomenon reflecting the underlying rules which determine what is valid communication in any given situation. These are not just linguistic rules relating to well-formed utterances concerning syntax and spelling but the rules of discourse, the rules governing the very discursive activity which adds weight to arguments in communication in action leading to a decision. By describing these rules, there emerges a profile that reflects an organization's potential to deal with change and innovation. The method used to describe discursive practice is discourse analysis.

\section{Discourse analysis as a tool}

Discourse analysis is not aimed at describing communication-in-action which is a surface phenomenon. It is a tool to decipher the underlying rules of discourse which govern valid communication, the deep structure providing impact to arguments and directing the way they contribute to the decision making process. Discourse analysis reveals the grid which determines the relative value of arguments in a specific communicative exchange.

Analysing a system by deciphering the rules of discourse requires data gathering and interpretation for which three sources are available. These are (1) observed actual communication-in-action, (2) the opinion of the individuals who derive their identity from being part of the system and (3) the semiological domain which is the sediment of discourse: the corpus of texts, symbols, images and/or rituals in and by means of which a social system maintains its identity over time and in relation to its environment. Each of these three approaches to the description and analysis of discourse requires and employs a different set of research designs and tools. Taking actual communication as it happens as an approach to deciphering the underlying rules of discourse calls for observing and interpreting verbal and non-verbal behaviour and rituals by means of structured schedules and coding schemes known as (participating) "conversation analysis" [44].

The second approach to discourse analysis is based on interrogating the individuals deriving their identity from belonging to that system on the dominant rules of discourse. In this approach, the toolbox of the social sciences stands to use including (but not limited to) questionnaires, interviews and group sessions (focus groups). The same variety holds for the analysis of the sediment of discourse-the corpus of text, symbols and 
images which is the sustainable residue of past communication [55]. These can take the form of signature stories, "narratives with a strategic message" which can "provide inspiration and direction both inside and outside the firm" [56]. According to Luhmann [54], an autopoietic view of organizational identity takes the production, analysis and interpretation of texts as point of departure. "What each organization is actually about, is reflected in the texts" [47]. In analysing texts, discourse analysis acts as a tool to assess the set of values that appear as supporting force of arguments in discussions leading to decisions. Discourse analysis assesses an organization's potential to adopt change and implement measures aimed at quality improvement.

In the case of health delivery organizations, the analysis is more difficult as they are compound organizations with a high degree of structural complexity in which several social systems have to interact and co-operate within the same corporate agenda in order to absorb change and adopt innovation $[5,57,58]$. The resulting tensions can be demonstrated and analysed by applying discourse analysis to the several distinctive systems within the organizations and to analyse the dynamics of their discursive interactions.

\section{Results and discussion}

In order to demonstrate the value of discourse analysis as a tool to assess an organization's accessibility for innovation, we present two examples concerning patient participation in decisions about individual health care.

\section{Two cases}

One driver for innovation in health care is the introduction of the concept of shared decision-making as a tool for quality improvement on the dimension of patient orientation [59]. In terms of communication-in-action, shared decision-making means that the functions of addresser and addressee are attributed equally to doctor and patient, thereby guaranteeing equivalent power distribution within the communicative interaction. Shared decision-making is called for in a situation "where, clinically, there are several treatment options available and the choice of the best treatment for a particular patient requires value judgements on the part of the patient and physician" [59]. As such, shared decision-making has been identified as "the very essence of patient-centered care and as a key part of change for improved quality and safety in healthcare" [59].

Shared decision-making is especially called for in situations where medical treatment has ceased to offer improvement in the patient's condition or quality of life. End-of-life decisions have to be made, including options for palliative care and/or acceptable modes of physician-assisted death (PAD) [60]. The procedure which leads to a (shared) decision is eminently suited to reveal the prevailing rules of discourse in the social system of a health care organization. For both the patient and the physician, the urge to come to a mutually accepted complexity reduction as context for decisions and ensuing action is pressing and the stakes are high, both personal and societal.

In the limited space of this paper, we present two examples of (opposing) discursive strategies characterizing a social system's ability to adopt shared decision making as a quality innovation, based on PAD as an example. The first is "A template for non-religious-based discussion against euthanasia" by Bloodworth et al. [61]. The second is a "viewpoint" by 
Quill et al. [62], why physician-assisted death (or PAD) should be made legally available to terminal patients.

The leading question in analysing the two documents would be "which discursive strategies are embedded in the 'template' and the 'viewpoint', determining the position of the patient and his/her interests in shared decision making?" Here, we are looking for the way arguments are presented in favor or against PAD (as an example of shared decision-making) in both documents. In doing this, we can assess the propensity of both groups to comply with patient oriented/initiated change in health care delivery. The question can be specified in three sub questions:

1. "To what extent is patient participation recognized as a source of impact of arguments?" (aspects of legitimacy).

2. "Which weight is attributed to patient oriented interests relative to other interests?" (aspects of value).

3. "Which impact is assigned to tradition vs innovation in relation to change?" (aspects of change readiness).

Linguistic discourse analysis is a research area characterized by methodological pluriformity $[63,64]$. There is no standard method to select or analyse a text-isolated or as part of a larger corpus of related texts. Choice of method tends to be purpose oriented. For our purpose, it will be sufficient to perform a basic pragmatic analysis: the analysis of meaning in context, or the study of what is intended by a speaker. This process of interpretation has two phases: the heuristic phase in which significant utterances (phrases) are identified based on formal criteria, and the attribution phase where the phrases are classified and arranged according to a scheme based on the requirements of a specific research question. In this example, we identify key concepts by marking text phrases based on frequency of occurrence, patterns of repetition, opposition, parallelism and typographic features like stress italics and/or "citation" as marker for authority. Then, we proceed by attributing these key concepts to our frame of reference: the sources of impact matrix (Table 1). In a final synthesizing operation, we summarize the concepts and condense them into a single characterizing statement per cell of the matrix.

\section{Example one: a closed system}

The authors of the "template" are medical professionals at Vanderbilt School of Medicine (Nashville, TN) and firmly embedded in the Catholic religious community. The template was published in the official journal of the Catholic Medical Association, the "oldest journal in existence dedicated to medical ethics" aiming at "providing a forum in which faith and reason can be brought to bear on analyzing and resolving ethical issues in health

Table 1 The innovation profile

\begin{tabular}{lll}
\hline Arguments: sources of impact & & \\
\hline I legitimacy & || value & ||I change readiness \\
\hline Leadership & Provenance & Tradition as authority \\
Inclusiveness & Currency & Concept of evolution \\
Governance & Quantity & Self-assessment \\
\hline
\end{tabular}


care, with a particular focus on issues in clinical practice and research" (http://www.cathmed.org/resources/linacre-quarterly/).

The background of the authors and the journal of publication strongly suggest that the text represents the discursive practice of at least a substantial part of religiously inspired medical professionals and provides as such a good illustration of the rules of discourse that determine this particular social system. From this perspective, the answer to the three leading questions runs like this:

1. Equal status in discourse as precondition for impact of arguments. Participating in a discursive exchange, taking part in a communication in which arguments are pitted against each other in order to reach a decision, reveals as its most important precondition the equality and autonomy of those involved in the exchange. All three authors of the template set out to restrict this crucial precondition by reducing the very concept of patient autonomy on this topic: "It is exceedingly common in pro-euthanasia circles to hear the argument that patient autonomy is the sole basis for moral decision making...such a morality (one based exclusively on the ability of individuals to choose whatever they believe is right for them in an effort to exert control over their circumstances) is fundamentally flawed". How do the three authors elaborate on this general observation, supporting the a-priori? Melissa Bloodworth. Patient autonomy is not absolute but relative: "autonomy in isolation reflects a society which has yielded to the reign of indifferent cruelty". The patient is denied his/her freedom of choice, being dependent on the physician to balance his/her arguments against other sources of impact such as "justice" and "beneficence".

Nathanial Bloodworth. Patient autonomy is never an ultimate quality ("Autonomy alone can never be a substitute for moral reasoning") and arguments referring to an independent position might in fact be deceitful, resulting from patients, "submitting their will to coercion" by friends and relatives who cannot be bothered by a drawn-out dying process.

E. Wesley Ely reduces the impact of arguments referring to on a patient's autonomy by invoking Aristotle who said that "the activity of intellect will only grant complete happiness if it be allowed a complete term of life", thereby suggesting that the patient who argues for euthanasia based on exercising his autonomy is in fact harming his "complete happiness" as a human being. All three authors disqualify the patient's position as an autonomous actor, thereby reducing the impact of the arguments presented by the patient in the discursive process. The authors do not deny autonomy as such-they frame autonomy as a derivative-or relative-concept, thereby reducing the impact of arguments referring to this autonomy as a condition for full participation in communication in action.

2. The impact of arguments is derived from the values to which they refer. In the template, patient-centered values are presented as individual and situational as opposed to physicians' values which are universal and as such provide superior weight to arguments.

Melissa Bloodworth. The medical value system, the essence of which is the Hippocratic primum non nocere, is "built upon the foundations of society itself", 
whereas the patients desire for a humane death by euthanasia counts as "murder" veiled as an "act of compassion".

Nathanial Bloodworth. The patient's desire for "a death free from suffering" conflicts with the physician's imperative for "moral reasoning" resulting in the refusal to "apportion death". The physician retains the moral upper ground while the patient is driven by an understandable but morally inferior desire for comfort in dying, enticing the physician into complicity to an immoral act.

E. Wesley Ely. The physician's ethics in refusing (PAD) rest in the concept of life itself as the "fundamental unalienable right" which supersedes all others including the patient's "freedom" to make private decisions. Being human points "to something or someone other than oneself". The desire to decide on one's own way of dying is presented as self-centered and therefore non-human.

All three authors oppose the personal values of the patient seeking relief in the process of dying to the superior values of the physician, representing a universal level of humanity to which the patient will have to subordinate his or her personal and individual interests.

3. Tradition vs innovation. As shared decision-making is a vehicle for quality improvement in healthcare as well as an innovation in its own right, it is important to assess the impact of arguments resting on innovation and the status of tradition.

Melissa Bloodworth. The arguments of patients pleading for a "good death" stand against the traditional "established practice of medicine" as the standard of a "trustworthy and hopeful profession" which "the darkness of death and suffering cannot erode"-in spite of death and suffering by the patient.

Nathanial Bloodworth. The physician is powerless against the immutable principles of the medical profession itself. The role of the physician is "sharply, firmly and immutably distinct" from answering pleas for a humane death. In this threefold repetition of the rejection of a possible compromise, any perspective of change is closed for all eternity.

E. Wesley Ely. Aristotle's Nicomachean Ethics provides the foundation for the decision that life must be prolonged to its natural end. This is a manifestation of "natural law which is universal and based on the rational nature of humans". As a consequence, "helping someone commit suicide" is not an act of benevolence but it is "confused thinking".

Not just the venerable tradition of the medical profession, but natural law and human rationality combined oppose changes in the position of the physician regarding the request for a humane death by the dying.

\section{Example two: an open system}

An alternative discursive strategy for complexity reduction in order to reach end-of-live decisions is demonstrated by Quill et al. [62] in their "viewpoint" in the JAMA.

The authors of this viewpoint, Quill, Back and Susan D. Block are medical professionals and involved in the world of palliative care, cancer research and oncology. They argue why physician-assisted death (or PAD) should be made legally available. The answers to the three research questions is: 
1. Equal status in discourse as precondition for impact of arguments. No doubt about it: with Quill et al., the ultimate decision to administer a merciful death also rests with the physician as warranted by law. However, the decision concerning a physician's assistance in ending a terminally ill patient's life is reached on the basis of an explicit and structured inquiry in which the physician questions the patient on his or her feelings, fears, experiences and desires regarding the impending death. Within this frame of "question and answer", the patient's influence on the physician's decision is formally guaranteed, thereby distributing "agency" as evenly as possible within applicable legal conditions.

But the decision is not reached by just physician and patient. Additional arguments can be provided by "family and friends" on the patient's side and by "trusted colleagues" on behalf of the physician. Quill et al. plead for an "open system with second opinions and consultations", thereby maximizing the inclusiveness of the social system reaching a decision.

As to governance: in dealing with "hastening death", the authors plead for a legalized context in which patients and physicians should not have to "act in secrecy" and can "experience benefits" provided by an open legal process, thereby fulfilling the strongest requirement for governance: regulation by law.

2. The impact of arguments is derived from the values to which they refer. Quill et al. state their position right from the start: "both the living experience of a person with a serious illness as well as commonly recognized ethical principles provide guidance in answering the question concerning the justifiability of physician assisted death". This means that the patient's perspective dominates the exchange of arguments (within the confines of societal accepted ethics). The physician's set of values should stand back against those of the patient-physicians should respond to the patient's concerns and fears "regardless of (...) their own stance". The same goes for the nature of the values referred to. The values with the strongest impact in the decision making process are those referring to the patient's "right to bodily integrity" and his/her desire to "have control over their own bodies, their own lives...".

Values like these are by their very nature non-quantifiable-which means that their impact cannot be counted by numbers. It will be the support of interest groups for the arguments as well as the emotional passion and the rhetorical force with which they are presented which determine the impact of arguments in discourse leading to a decision pro or contra legalizing PAD.

3. Tradition vs. innovation. Change readiness as a source of impact is not very well realized in this "viewpoint". No extra-situational authority is cited as an argument (besides the force of law) and neither are concepts of progress in pro- or contra end-of-life decisions. As to the image of self: in this "viewpoint", the physician is primarily focused on exploring and working with a patient requesting PAD and is subservient to the patient's desires, unless physicians “...cannot morally tolerate their (own) participation" in which case they should refer the patient to another physician. Within this role concept, the physician will be open to change if warranted by manifest patient interest-and so should the legal system.

Arguments for legalizing PAD in this "viewpoint" as discursive situation derive their impact primary from reference to the justified interest of the patient wanting 
to avoid anxiety, pain and physical decay in the process of dying. The argument is supported by projected safeguards against arbitrariness, coercion and slippery-slope arguments and by reference to states and countries where PAD is legalized without any of the feared side effects.

In analysing (as an example) two texts pro and contra PAD by two groups of medical professionals, we demonstrated that it is not their training a physicians nor their formal status as health care providers in a hospital organization which determine their position vis-à-vis patient participation in a decision vital to the patient. The two groups differ in their set of values, their concepts of legitimacy/ authority and their orientation toward the tradition of their profession. These underlying differences become visible in discursive strategies used to convince the reader of both texts of the correctness of the position taken by each group. Knowledge of these underlying (group) profiles is vital as precondition for the selection and successful implementation of innovation and to map possible sources of tension between factions within the organization.

\section{Discussion}

We provided two examples, how a discursive strategy reduces a complex reality - the situation of a terminal patient who depends on a physician to realize/her desire of a "good death" - to a version of that reality in which a decision can be reached. Transmitted to the impact matrix, the rules of discourse underlying the "template" can be summarized like this (Table 2):

The social system of medical professionals as it appears in the template and is summarized in the matrix is that of a closed, self-centered and conservative community, motivated by its own version of patient's best interest and bound by the narrow confines of a specific version of medical convention.

A social system like this will only respond to a limited kind of incremental innovation within existing (medical) practice. More fundamental, disruptive change will be met with well-argued resistance as the epiphenomenon of hardcore immunity to change, which will only be broken by an event [65] or-in modern vernacular-a "game changer" [66] which renders obsolete today's best practice and the organizations which thrive by it.

In the discursive strategy of the "viewpoint", there is hardly any reference to tradition, external authority and/or superficial norms or standards inhibiting change and implementation of innovation such as legalizing PAD. The only reference to external sources

Table 2 Example 1 "template"

\begin{tabular}{lll}
\hline Arguments: sources of impact & & \\
\hline I legitimacy & II value & III change readiness \\
\hline Leadership & Provenance & Tradition as authority \\
Decisions lie exclusively with physician & $\begin{array}{l}\text { Physician's values supersede } \\
\text { patient's }\end{array}$ & $\begin{array}{l}\text { Reference to founding father } \\
\text { of medicine Hippocrates }\end{array}$ \\
Inclusiveness & Currency & Concept of evolution \\
$\begin{array}{c}\text { Patient's status as participant depends } \\
\text { on physician }\end{array}$ & $\begin{array}{l}\text { Moral values based on } \\
\text { deontological ethics }\end{array}$ & Principles of medicine are immutable \\
$\begin{array}{c}\text { Governance } \\
\text { Decisions are made unilaterally based } \\
\text { on professional status }\end{array}$ & Quantity & Image of self \\
\hline
\end{tabular}


of impact is to those states and countries which set an example deemed worth to be followed (Table 3).

The social system of medical professionals as it appears in the "viewpoint" and is summarized in the matrix is that of a community open to patient participation and shared decision-making based on the patient's representation of his/her interest, limited only by the boundaries of law and invoking the good examples of other states and countries as inspiration. A social system like this is an open system which will adapt to innovation and quality improvement based on shared decision-making as long as it is in the proven best interest of patients. Of course, it should be clear that findings based on a single linguistic analysis are insufficient to draw far-reaching conclusions about the degree of openness of a social system. In order to complete the innovation profile, a "three-point analysis" is required, including (participating) conversation analysis and questioning participants in the discussion.

The second restriction is that the willingness of medical professionals to participate in innovation does not guarantee the implementation of an innovation in the health care organization. Doctors are but a subset-or a subsystem-of medical professionals within a much larger complex organization where several different situational logics compete for dominance in a battle of interests in a world of limited resources. A comprehensive analysis of a hospital's innovation potential should include a multifactorial analysis of all relevant social (sub)systems involved as well as the dynamics of their (discursive) interaction.

\section{Conclusions}

Quality improvement of healthcare and health care delivery through structure and process innovation can only be successful-yielding sustainable outcomes at acceptable costs-under the condition that both the nature of the intervention and the chosen method of implementation are compliant with the potential of an organization for innovation and change. The difficulty is how to assess this potential. As multiple reviews have shown, an organization's formal properties as rational, productive system or the individual characteristics of its members are poor predictors of successful innovation. It is the nature of legitimacy, the set of shared values and the perception of evolution which determine the innovation culture of an organization. In the healthcare sector, those three determinants pose extra challenges as they tend to differ for the

Table 3 Example 2 "viewpoint"

\begin{tabular}{lll}
\hline Arguments: sources of impact & & \\
\hline I legitimacy & II value & III change readiness \\
\hline $\begin{array}{l}\text { Leadership } \\
\begin{array}{l}\text { Decision making is shared between } \\
\text { physician and patient }\end{array}\end{array}$ & $\begin{array}{l}\text { Provenance } \\
\text { Patient's values prevail over } \\
\text { physician's }\end{array}$ & Tradition as authority \\
$\begin{array}{l}\text { Inclusiveness } \\
\begin{array}{l}\text { Besides patient, family/friends and } \\
\text { colleagues participate }\end{array}\end{array}$ & $\begin{array}{l}\text { Non numerical: autonomy, } \\
\text { integrity, quality of life }\end{array}$ & Concept of evolution \\
$\begin{array}{l}\text { Governance } \\
\begin{array}{l}\text { Decisions are reached in an objective } \\
\text { and transparent way }\end{array}\end{array}$ & $\begin{array}{l}\text { Quantity } \\
\text { Non-applicable }\end{array}$ & \begin{tabular}{l} 
Image of self \\
Change driven by patient's needs \\
\hline
\end{tabular} \\
\hline
\end{tabular}


different groups of stakeholders working together within the same organizational setting and policy agenda.

The analysis of two (mini)-systems has shown how two groups of similar professionals-all physicians and well embedded in the professional institutional environment-operate with different discursive strategies in the complex issue of end of life decisions, thereby reaching different outcomes: a plea for or against a legally embedded right to physician-assisted death in the case of terminally ill patients. An analysis of an organization's innovation potential by means of mapping its discursive strategies can reduce the risk of setting unattainable goals by adjusting the selection of innovations and the design of implementation processes to the identity of the organization which is expected to adopt them.

In our examples, it remains to be seen, whether the innovation profile of the two social systems shown in the PAD discussion persists in other-but similar-situations. In other words, are the observed discursive strategies related to the issue at stake (PAD) or are they truly a marker of a system's innovation profile and hence a predictor of future behaviour? In order to decide the issue, further tests and analysis are required to confirm or adjust the initial hypothesis.

\section{Authors' contributions}

PK, JO, MS and PB have jointly designed the research program; PK has initiated this particular study and drafted the manuscript; JO has contributed to the sources of impact matrix; PK and MS have independently performed the discourse analysis; and all authors read and approved the final manuscript.

\section{Authors' information}

The authors of the research paper are experienced professionals in the health care sector with a substantial track record in quality improvement and change management, both as general managers and teachers and as researchers with the Chair of Quality Improvement in Heath Care of Inholland University of Applied Sciences, Amsterdam. Pieter Kievit (MA, MBA) is CEO of the West Frisian Academy of the combined Westfries Medical Centre (Hoorn) and the Waterland Hospital (Purmerend) and as such responsible for quality and safety of medical research and the education of medical specialists. He is a fellow of the Chair of Quality Improvement in Heath Care at Inholland University of Applied Sciences, Amsterdam.

Jeanette Oomes (MA) and Marianne Schoorl (PhD) are both quality assurance officers in the field of laboratory medicine and fellows of the Chair of Quality Improvement in Heath Care at Inholland University of Applied Sciences, Amsterdam.

Piet Bartels (PhD) is former CEO of laboratory services at Noord West Zorggroep (Alkmaar and Den Helder) and Chair of Quality Improvement in Heath Care at Inholland University of Applied Sciences, Amsterdam.

\section{Ethics approval and consent to participate}

As this is a non-experimental, non-interventional study not involving patients, patients' tissue and/or data, an ethics approval or waiver thereof does not apply.

Competing interests

The authors declare that they have no competing interests.

\section{Publisher's Note}

Springer Nature remains neutral with regard to jurisdictional claims in published maps and institutional affiliations.

\section{Author details}

${ }^{1}$ West Frisian Academy, Westfries Medical Centre, Maelsonstraat 3, 1624 NP Hoorn, the Netherlands. ${ }^{2}$ North West Medical Centre, Alkmaar, the Netherlands.

Received: 4 September 2017 Accepted: 21 May 2018

Published online: 31 May 2018

\section{References}

1. Rogers EM (2005) Diffusion of innovations. Free Press, New York

2. Donabedian A (1988) The quality of care. How can it be assessed? JAMA 260(12):1743-1748

3. Ayanian A, Markel H (2016) Donabedian's lasting framework for health care quality. N Engl J Med 2016; 375:205-207. DOl: https:/doi.org/10.1056/NEJMp1605101

4. Grol R, Wensing M (2013) Implementation of change in healthcare: a complex problem. In: Grol R, Wensing M, Eccles M, Davis D (eds) Improving patient care: the implementation of change in health care, $2 n d$ edn. Wiley-Blackwell, London 
5. Scott WR (2014) Institutions and organizations: ideas, interests and identities. Sage Publications, Thousand Oaks

6. Lincoln J, Kalleberg A (1990) Culture, control and commitment: a study of work organization and work attitudes in the United States and Japan. Cambridge University Press, Cambridge/New York

7. Orru M, Biggart N, Hamilton G (1997) The economic organization of East Asian capitalism. Sage, Thousand Oaks

8. Scott WR, Ruef MM, Caronna C (2000) Institutional change and health care organizations. From professional dominance to managed care. University of Chicago Press, Chicago

9. Hogg M, Terry D (eds) (2001) Social identity processes in organizational contexts. Taylor \& Francis Group, New York

10. Scott WR, Davis GF (2006) Organizations and organizing: rational, natural and open system perspective. Pearson Prentice Hall, Englewood

11. Capra F, Luisi P (2014) The systems view of life, a unifying vision. Cambridge University Press, Cambridge

12. Maier NRF (1965) Differences and disagreement as factors in creative group problem solving. J Appl Behav Sc 1(4):373-386

13. Scott WR (1987) The adolescence of institutional theory. Adm Sci Q 32(4):493-511

14. Kline SJ, Rosenberg N (1986) An overview of innovation. In: Landau R, Rosenberg N (eds) The positive sum strategy: harnessing Technology for Economic Growth. National Academy Press, Washington, D.C.

15. Schulingkamp RC, Latham JR (2015) Healthcare performance excellence: a comparison of Baldrige award recipients and competitors. QMJ 22(3):6-22

16. Griffith JR (2009) Finding the frontier of hospital management. J Healthc Manag 54(1):57-72

17. Lee D (2016) HEALTHQUAL: a multi-item scale for assessing healthcare service quality. Serv Bus. https://doi.org/10 1007/s11628-016-0317-2

18. Lee D, Kim KK (2017) Assessing healthcare service quality: a comparative study of patient treatment types. Int J Qual Innov 3:1. https://doi.org/10.1186/s40887-016-0010-5

19. Berwick DM (2003) Disseminating innovations in health care. JAMA 289(15):1969-1975

20. Greenhalgh T, Robert G, Bate P, Macfarlane F, Kyriakidou O (2005) Diffusion of innovations in health service organizations, a systematic literature review. BMJ books, Oxford

21. Grol R, Wensing M (2013) Implementation of change in healthcare: a complex problem. In: Grol R, Wensing M, Eccles M, Davis D (eds) Improving patient care: the implementation of change in health care. Wiley-Blackwell, London

22. Institute of Medicine (2001) Crossing the quality chasm: a New Health System for the 21st Century. Committee on Quality of Health Care in America. National Academy Press, Washington DC

23. Meissner J, Sprenger M (2011) Mixing methods in innovation research: studying the process-culture-link in innovation management. Hist Soc Res 36(1):180-198

24. Länsisalmi H, Kivimäki M, Aalto P, Ruoranen R (2006) Innovation in healthcare: a systematic review of recent research. Nurs Sci Q 19:66-72

25. Gawande A (2012) Big Med, Restaurant chains have managed to combine quality control, cost control, and innovation. Can health care? The New Yorker, August 13, 2012

26. Denning S (2012) How not to fix US health care: copy the cheesecake factory. Forbes August 13, 2012

27. Berwick DM (2016) Era 3 for Medicine and Health Care. JAMA 315(13):1329-1330. https://doi.org/10.1001/jama.-2016.1509

28. De Vries H. A, Tummers LG, Bekkers VJJM (2018). The diffusion and adoption of public sector innovations: a metasynthesis of the literature. Perspectives on Public Management and Governance. Accepted version https://www. ris.uu.nl/ws/files/42298127/. Accessed 9 May 2018

29. Rogers EM (ed) (2003) Diffusion of innovations. Free Press, New York

30. Cummings T, Worley CG (2008) Organization development and change. South Western Cengage Learning, Mason

31. Bakken T, Hernes T, Wiik E (2009) An autopoetic understanding of "innovative organization". In: Magalhaes R, Sanchez R (eds) Autopoiesis in organization theory and practice. Emerald Group Publishing Limited, Bingley

32. Kegan R, Lahey L (2009) Immunity to change. Harvard Business Press, Boston

33. Reay TCR, Hinings B (2009) Managing the rivalry of competing institutional logics. Organ Stud 30(6):629-652

34. Provan KG, Kenis P (2007) Models of network governance: structure, management and effectiveness. J Public Adm Res Theory 18:29-252

35. Kirkpatrick L, Bulliger B, Dent M, Lega F (2012) The development of medical manager roles in European hospital systems: a framework for comparison. Int J Clin Pract 66(2):121-124

36. Degeling PJ, Maxwell S, ledema R, Hunter DJ (2004) Making clinical governance work. BMJ 329:679-682

37. Greenwood R, Raynard M, Kodeih F, Micelotta E, Lounsbury M (2011) Institutional complexity and organizational responses. Acad Manag Ann 5(1):317-371

38. Glouberman S, Mintzberg H (2001) Managing the care of health and the cure of disease - part I: differentiation. Health Care Manag Rev 26(1):56-69

39. Greenhalgh T, Stones R, Swinglehurst D (2014) Choose and book: a sociological analysis of 'resistance' to an expert system. Soc Sci Med 104:210-219

40. Kabat GC (2016) Getting risk right: understanding the science of elusive health risks. Ch 3 When risks go viral, biases and bandwagons. Columbia University Press, New York

41. Wolf $\mathrm{P}$, Meissner J (2010) Methods for qualitative management research in the context of social systems thinking. Forum: Qualitative Social Research, 11 (3). http://www.qualitative-research.net/index.php/fqs/article/view/1548/3055. Accessed 9 May 2018

42. Luhmann N (2000) Organisation und Entscheidung. Westdeutscher Verlag, Opladen/Wiesbaden

43. Heritage J, Clayman S (2012) Talk in action: interactions, identities and institution. Wiley-Blackwell, Hoboken

44. Goodwin C, Heritage J (1990) Conversation analysis. Annu Rev Anthropol 19(1):283-307

45. Seidl D (2005) Organizational identity and self transformation: an autopoetic perspective. Adgate, Aldershot

46. Kneer $\mathrm{G}$ (2001) Organization and society, on the unresolved relationship between organizational and function systems in Luhmann's theory of social systems. Zeitschrift für Soziologie, Jg 30, Heft 6:407-428

47. Hernes T (2008) Understanding organization as process. Theory for a Tangled World, chapter 5. Niklas Luhmann on Autopoiesis and Recursiveness in Social Systems. Routledge, London/New York

48. Jakobson R (1960) Linguistics and Poetics. In: Sebeok T (ed) Style in Language. M.IT. Press, Cambridge, pp 350-377 
49. van Dijk TA (1989) Structures of discourse and structures of power. In: Anderson JA (ed) Communication Yearbook 12. Routledge, New York/London, pp 18-59

50. Braun J (2012) Selbstbestimmung und Fremdbestimmung. Über die Schwierigkeit autonomen Handelns in einer heteronom bestimmten Gesellschaft. Rechtstheorie 43(2):159-175. https://doi.org/10.3790/rth.43.2.159

51. Bevir M (ed) (2010) The sage handbook of governance. Sage, Berkeley

52. Rihani S (2002) Complex systems theory and development practice. Understanding non-linear realities. Zed Books, London

53. Babbie E (2011) The basics of social research. Wadsworth Cengage Learning, Belmont

54. Luhmann N (1997) Theory of society, vol I. Stanford University Press, Stanford

55. Teubert W, Cermakova A (2007) Corpus linguistics: a short introduction. Continuum, London

56. Aaker D, Aaker JL (2016) What are your signature stories? Calif Manag Rev 58(3):49-65

57. Fitzgerald F, Ferlie E, Hawkins C (2002) Interlocking interactions, the diffusions of innovations in healthcare. Hum Relat 55:1429-1449

58. Glenn R, Greenhalgh T, MacFarlane F, Peacock R (2009) Organizational factors influencing technology adoption and assimilation in the NHS: a systematic literature review, report for the National Institute for Health Research Service Delivery and Organisation programme

59. Charles C, Gafni A, Whelan T (1997) Shared decision making in the medical encounter: what does it mean? (or it takes at least two to tango). Soc Sci Med 44(5):681-692

60. Godolphin W (2009) Shared decision making. Healthc Q 12(special nr):186-190

61. Bloodworth M, Bloodworth N, Ely WE (2015) A template for non-religious-based discussion against euthanasia. Linacre Q 82(1):49-54. https://doi.org/10.1179/2050854914Y.0000000036

62. Quill TE, Back AL, Back SD (2016) Responding to patients requesting physician-assisted death. JAMA Viewpoint 315(3):245-246

63. Bluhm C, Deissler D, Scharloth J, Stukenbrock A (2000) Linguistische Diskursanalyse: Überblick, Probleme, Perspektiven. Sprache und Literatur in Wissenschaft und Unterricht 31, H 86:3-19

64. Jorgensen M, Phillips $L J$ (2002) Discourse analysis as theory and method. SAGE Publications Inc., Thousand Oaks

65. Luhmann N (1995) Social systems. Stanford University Press, Stanford

66. McAdams D (2014) Game-changer: game theory and the art of transforming strategic situations. W.W Norton \& Company, New York

Submit your manuscript to a SpringerOpen ${ }^{\odot}$ journal and benefit from:

- Convenient online submission

- Rigorous peer review

- Open access: articles freely available online

- High visibility within the field

- Retaining the copyright to your article 